\title{
Developing practice guidelines for anesthesia services in rural Canada: the importance of the family physician perspective
}

\author{
Vaibhav A. Kamble, MD (1) Beverley A. Orser, MD, PhD • C. Ruth Wilson, MD
}

Received: 5 May 2020/Accepted: 7 May 2020/Published online: 12 June 2020

(C) Canadian Anesthesiologists' Society 2020

\section{To the Editor,}

The goal of the Guidelines to the Practice of Anesthesia ${ }^{1}$ published annually by the Canadian Anesthesiologists' Society (CAS) is to promote safe and timely anesthesia care for all Canadians. This goal can only be achieved if physicians with the right clinical skills are available to the right patients in the right environment. We have concerns about how the 2020 edition of the Guidelines portray the provision of anesthesia care for rural Canadians in stating that:

"The Canadian Anesthesiologists' Society (CAS) acknowledges the fact that remote communities often lack the population base to support a specialist anesthesiology practice. In these communities, appropriately trained family physicians may be required to provide anesthesia services. In communities with the clinical volume to support full-time anesthesiologists,

The authors of the article: Can J Anesth 2020; 67: 64-99, respectfully declined an invitation to submit a reply to the above letter.

V. A. Kamble, MD (

Department of Anesthesiology and Pain Medicine, University of Toronto, Toronto, ON, Canada

e-mail: vaibhav.kamble@utoronto.ca

B. A. Orser, $\mathrm{MD}, \mathrm{PhD}$

Department of Anesthesiology and Pain Medicine, University of Toronto, Toronto, ON, Canada

Department of Anesthesia, Sunnybrook Health Sciences Centre, Toronto, ON, Canada

C. R. Wilson, MD

Department of Family Medicine, Queen's University, Kingston, ON, Canada fellowship-certified anesthesiologists should provide these services." 1 .

This statement suggests that clinical volumes determine the best anesthesia care provider, with specialists being the first choice and family practice anesthesia providers a second-in-line alternative. The first concern with these guidelines is feasibility-i.e., despite high clinical volumes across Canada, there simply are not enough specialists available to service urban and rural areas. For example, in 2019, the Yarmouth Regional Hospital in Nova Scotia, which serves 58,000 people, was left with one anesthesiologist trying to serve a hospital usually staffed with four. ${ }^{2}$

The second concern is that in the large and complex Canadian healthcare system, "best practices" for anesthesia services should be determined by a community's overall medical needs. For example, in Nunavut, the government funds only a limited number of salaried physicians. As such, Iqaluit (as with certain other remote communities) needs family physicians who can provide anesthesia care, not full-time specialists who are unable to support obstetric, inpatient medical, emergency, and office-based care. Other jurisdictions, such as Yellowknife in the Northwest Territories, are currently well served by locum specialists supporting a core group of family practice anesthesia providers.

For decades, family physicians with appropriate training-currently numbering at least 500-have been providing anesthesia care in rural communities, including Indigenous communities. Most have completed a Certificate of Added Competence in Family Practice Anesthesia, developed by the College of Family Physicians of Canada. This certificate requires training through an accredited University program and annual anesthesia-specific continuing professional development. 
The contributions of these physicians should be celebrated in the Canadian healthcare system and better reflected in the CAS' Guidelines.

In the future, we suggest that the CAS work with the College of Family Physicians of Canada, the Society of Rural Physicians of Canada, and the Collaborative Advisory Group for General and Family Practice Anesthesia to develop guidelines that better address the anesthesia needs of rural communities.

Disclosure None.

Funding statement None.
Editorial responsibility This submission was handled by Dr. Hilary P. Grocott, Editor-in-Chief, Canadian Journal of Anesthesia.

\section{Reference}

1. Dobson G, Chow L, Filteau L, et al. Guidelines to the practice of anesthesia-revised edition 2020. Can J Anesth. 2020;67:64-99.

2. Vibert, J; The Chronicle Herald. VIBERT: Yarmouth hospital crippled by exodus of anesthesiologists. Updated April 10, 2019. Available from URL: https://www.thechronicleherald.ca/opinion/ vibert-yarmouth-hospital-crippled-by-exodus-of-anesthesiologists298939/ (accessed May 2020).

Publisher's Note Springer Nature remains neutral with regard to jurisdictional claims in published maps and institutional affiliations. 